\title{
BEZOAR IN A SPOTTED DEER (AXIS AXIS)
}

\section{R. Kumar ${ }^{1}$, M.G. Nair ${ }^{1}$, K.C. Varshney ${ }^{1}$ and S. Ramalingam ${ }^{2}$}

${ }^{1}$ Department of Pathology, ${ }^{2}$ Department of Anatomy

Rajiv Gandhi College of Veterinary and Animal Sciences, Pondicherry 605009, India

An adult female Spotted Deer (Axis axis), which was maintained in the college livestock farm died suddenly and was presented for post mortem examination. The deer, originally located at the premises of a hotel at Pondicherry was handed over to the college by the forest department approximately six months prior to its death.

Blood smear examination did not reveal any organism of pathological significance. On necropsy, the rumen and reticulum were moderately impacted and among the contents was found a bezoar with knotted appearance (Fig. 1). It was $40 \mathrm{~cm}$. in length and $400 \mathrm{~g}$. in weight. The bezoar consisted of several entangled polythene bags, ingesta and mineral deposits. The omasum and abomasum contained moderately digested ingesta. Intestines showed mild enteritis. Other postmortem findings included hydrothorax, pulmonary edema, ecchymosis on epicardium and a focal necrotic calcified lesion on the parietal surface of the liver.

Presence of foreign bodies in the fore stomach of deer is not uncommon (Rao \& Acharyjo, 1995). Sharma and Chauhan (1997) reported the occurrence of phytobezoar in the reticulum of a Barking Deer in Nainital Zoo. The polythene bags left over by the visitors to the zoo was postulated to be the source of the bezoar. The occurrence of bezoar in the present case may be due to the fact that the animal had access to unwanted materials in the hotel premises.

Although this bezoar was found to be the cause of impaction, the cause of death in this case could be attributed to acute pulmonary edema.

The observation made in this case once again highlights the potential health hazard to wild and domestic animals as a result of improper disposal of plastic materials.

\section{Acknowledgement}

The authors are thankful to the Dean, Rajiv Gandhi College of Veterinary and Animal Sciences, Pondicherry for providing the facilities. Thanks are due to the staff members, Department of Animal Husbandry Extension for their help in photography.

\section{References}

Rao, A.T. and L.N. Acharjyo (1995). Foreign bodies in zoo animals and birds at Nandankanan Zoo. Indian J.Vet. Path. 19: 48-50.

Sharma, S.C. and R.S. Chauhan (1997). Phytobezoars in Barking Deer (Muntiacus muntjak). Indian J.Vet.Path. 21:168-169.

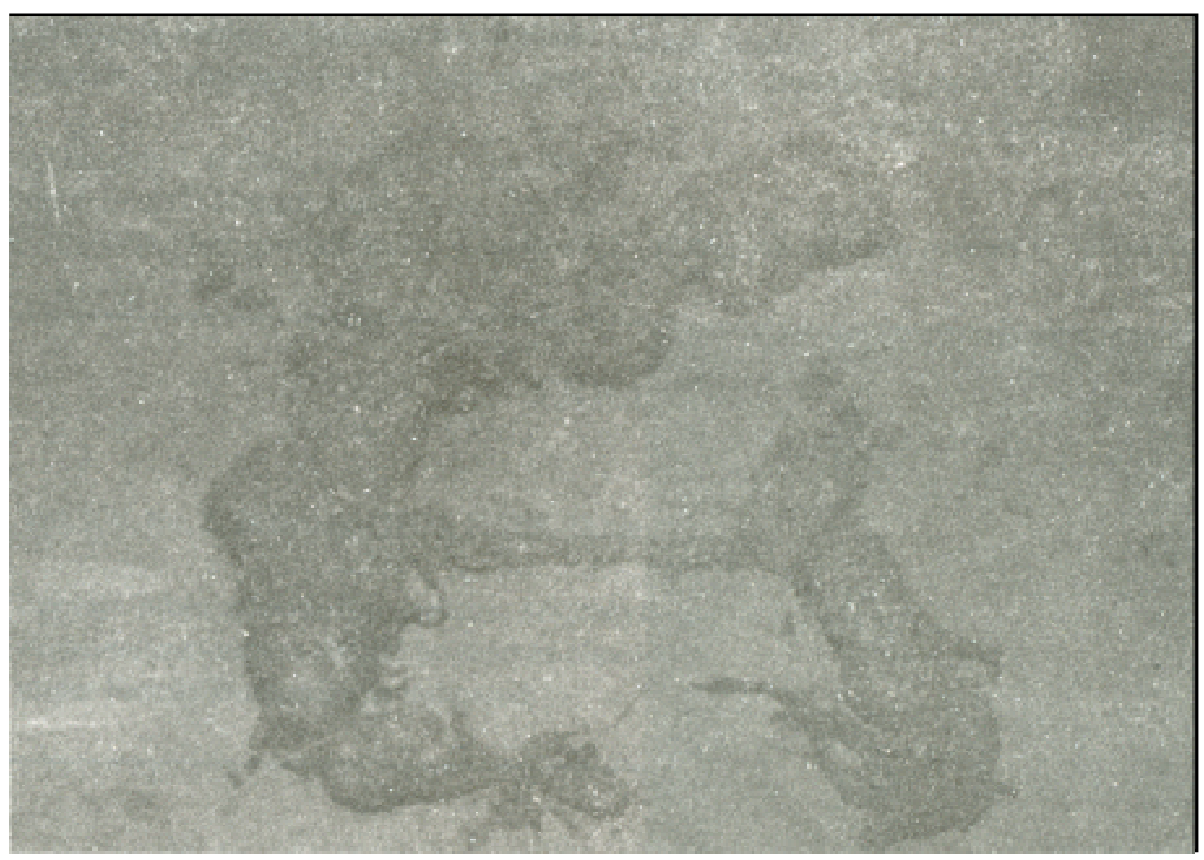

Figure 1. Bezoar consisting of polythene bags, ingesta and mineral deposits. 